\title{
Implementation and Design of New Functions for a Web-based E-learning System to Stimulate Learners Motivation
}

\author{
Keita Matsuo $\uparrow$, Leonard Barollit, Fatos Xhafa $\uparrow \dagger$, \\ Akio Koyama†t, Arjan Durresit†, Makoto Takizawałt \\ $\uparrow$ Graduate School of Engineering, Fukuoka Institute of Technology (FIT) \\ I Department of Information and Communication Engineering, FIT \\ 3-30-1 Wajiro-Higashi, Higashi-Ku, Fukuoka 811-0295, Japan \\ E-mail: bd07002@ws.ipc.fit.ac.jp, barolli@fit.ac.jp \\ $\dagger \dagger$ Department of Languages and Informatics Systems \\ Polytechnic University of Catalonia \\ Jordi Girona 1-3, 08034 Barcelona, Spain \\ E-mail: fatos@1si.upc.edu \\ $\dagger$ Department of Informatics, Faculty of Engineering, Yamagata University \\ 4-3-13 Jonan, Yonezawa 992-8510, Yamagata, Japan \\ E-mail: akoyama@yz.yamagata-u.ac.jp \\ $\$ \uparrow$ Department of Computer and Information Science \\ Indiana University Perdue University Indianapolis \\ 723 W. Michigan Street SL 280, Indianapolis, IN 46202, USA \\ E-mail: durresi@cs.iupui.edu \\ +tDepartment of Computers and System Engineering, Tokyo Denki University \\ Ishizaka, Hatoyama, Saitama 350-0394, Japan \\ E-mail: taki@takilab.k.dendai.ac.jp
}

\begin{abstract}
Due to the opportunities provided by the Internet, people are taking advantage of e-learning courses and during the last few years enormous research efforts have been dedicated to the development of e-learning systems. So far, many e-learning systems are proposed and used practically. However, in these systems the e-learning completion rate is low. One of the reasons is the low study desire and motivation. In our previous work, we implemented a e-learning system that is able to increase the learning efficiency by stimulating learners motivation. In this work, we designed and implemented new functions to improve the system performance.
\end{abstract}

\section{Introduction}

Due to the opportunities provided by the Internet, more and more people are taking advantage of distance learning courses. During the last few years enormous research efforts have been dedicated to the development of distance learning systems and many large projects have been established [1-7]. However, in these systems the e-learning completion rate is low. One of the reasons is the low study desire when the learner studies learning materials. Therefore, it is very important to stimulate learner's motivation during the study. 
There are several Web-based e-learning systems that consider the learner's capability and understanding [8-9]. In [8], the authors present MESIA system. The system is able to keep the teacher operating cost low and to offer fine education by the cooperation of Computer Assisted Instruction (CAI) and teacher. The system is able to recognize the learners who need assistance, but its main purpose is to support the teacher, not the learners. In [9], we proposed an agent based distance learning system to deliver appropriate studying materials to learners.

In order to offer a suitable and efficient study for learners, in our previous work [10], we proposed a Web-based distance learning system in order to increase learner's efficiency. The proposed system has three subsystems: learning subsystem, learner supporting subsystem and teacher supporting subsystem. The purpose of this system is to increase the e-learning completion rate by stimulate learner' motivation. We evaluated this system by several experiments and surveys and have shown that our previous system by using learner's study history, encourage function, ranking function, and self-determination of the study materials can increase the learning efficiency.

In this paper, we designed and implemented new functions in our system such as: interface changing function, new ranking function and learner's learning situation checking function.

The paper is organized as follows. The previous system structure is introduced in Section 2. In Section 3, we present the design and implementation of new functions. In Section 4, we discuss and compare the functions of the proposed system with other e-learning systems. Finally, we give some conclusions and future work in Section 5.

\section{Our Previous System}

The system structure is shown in Fig.1. The proposed system has three subsystems: learning subsystem, learner supporting subsystem and teacher supporting subsystem. The learning subsystem includes the studying materials, examination exercises, and some functions to stimulate learner's motivation. The learner supporting subsystem supports the learners when they have problems during the study. In this subsystem are implemented some interaction functions. The teacher supporting subsystem has some function to get the learning situation of learners and to give hints from the teacher to improve the learning efficiency.

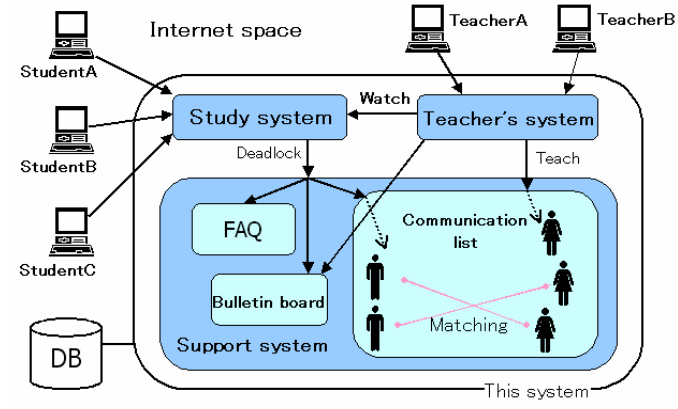

Fig. 1. System structure.

\subsection{Learning subsystem}

At the beginning, the learner by using the login and password enters the system. Next, he/she reads the text and if understands the text information starts to do the exercises. Then, the obtained results and ranking are shown in the computer display. After that, the learner decides the next items to study and the learning procedure is repeated again. If the learner does not understand some parts of the text, he/she moves to the learner support subsystem. After, he/she understands the text goes back to the learning subsystem.

\subsection{Teacher supporting subsystem}

In this subsystem, the person who is registered as teacher can enter the system by using the registered login and password. By using this subsystem, the teacher is able to judge the learning situation of the learners. The teacher can check the following items.

- The learners who are using the system.

- The items which are finished.

- The learner has problems with studying or not (is the learner using the learner supporting system or not).

- The FAQ of the learner support subsystem.

- The Bulletin Board (BB) of the learner support subsystem

If the teacher finds that a student is using the learner support subsystem, by using e-mail, the teacher can communicate with the learner. It is also possible to communicate with the learner by using Window Messenger (WM). If a learner has problems during the study, the teacher can use the e-mail and WM to communicate with the learner. By using WM, it is possible to have voice chat or video chat, while $\mathrm{BB}$ is used to explain the content that the learners do not understand. 


\subsection{Learner supporting subsystem}

The learner supporting system is used to help the learners when they have problems during the study. This subsystem includes:

- FAQ,

- BB,

- The list of persons who can communicate together.

The learner can investigates by FAQ whether there are answers of previous questions related with the content that the learner is studying or not. If there are not answers, the learner waits until the answer will be shown in the BB. If the learner needs the answer in a real time he enters in the member list. Then, the present learner can select a member who answered the questions in the previous test and communicate with him.

\subsection{Interactive functions}

The proposed system has the following communication modes.

- Communication between students.

- Communication between the student and teacher (question mode).

- Communication between the teacher and student (explanation).

\section{Design and Implementation of New Functions}

In this section, we present the design and implementation of new functions for our system. The page output is generated by using JSP. For the system logic, we use Java and Java Servlet. For the system database is used Postgresql.

The system works in the following way. At the beginning, the learner enters the study room. Next, the learner starts to study the learning materials. The teacher checks the learning situation and based on that decides how to support the learner. By using WM it is possible to have voice chat or video chat. Also, because the FAQ and learner support subsystem are linked in this page, they can be referred if are needed. The BB can be used by teacher to explain the content that the learners do not understand. If the learner understands the problem he asked the teacher, he goes back to the learning phase and starts again learning process. The e-learning flow is shown in Fig. 2. In order to check whether the learner is in the room or not we implemented a RFID system as shown in Fig. 3.

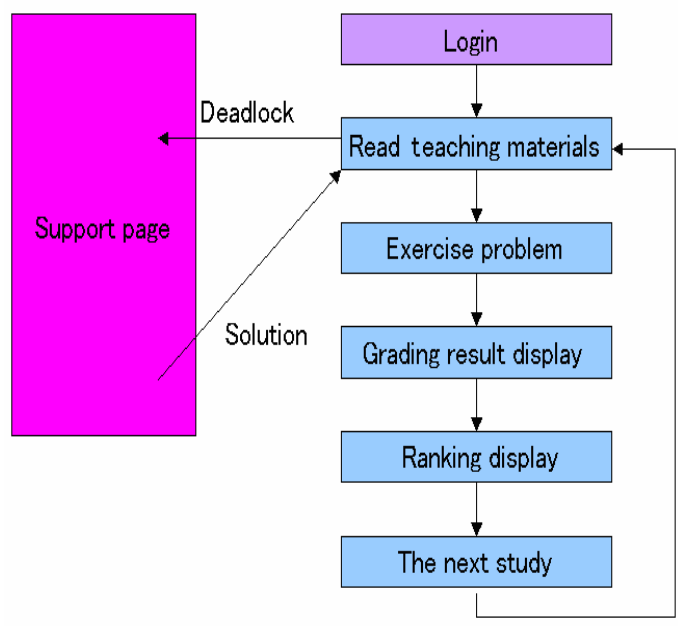

Fig. 2. E-learning flow.

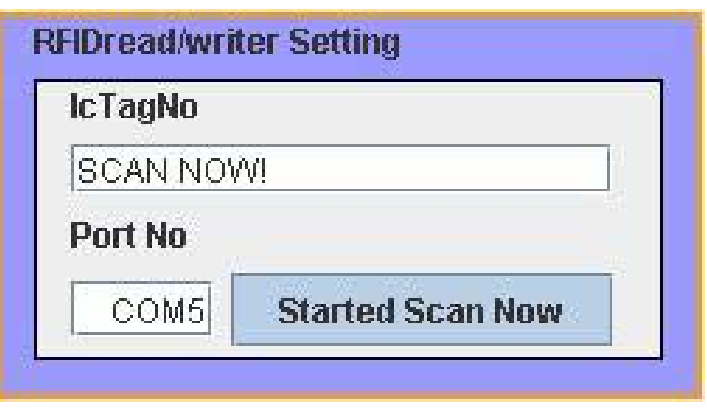

Fig. 3. RFID checking system.

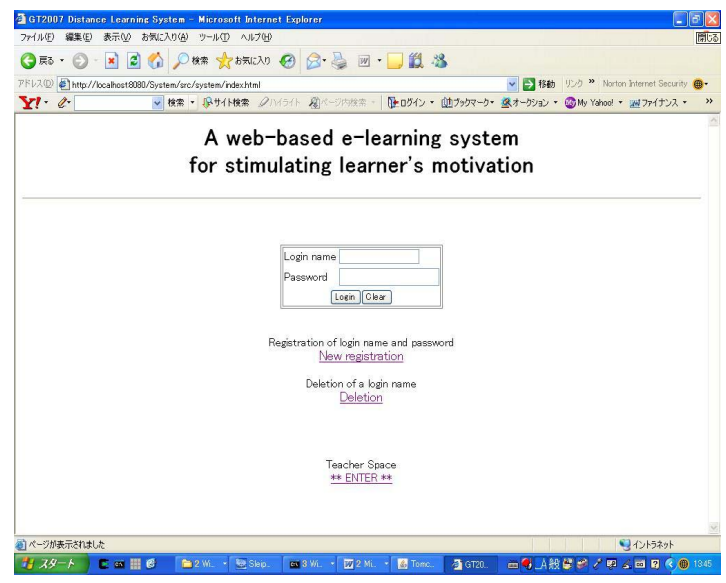

Fig. 4. System interface.

The implemented system interface is shown in Fig. 4. We will present in following its new implemented functions. 


\subsection{Visible motivation function}

In the previous procedure of the learning, it is very difficult to check the student's learning situation. For this reason we designed and implemented a new function. If a learner does not use the computer keyboard or the mouse for more than 20 minutes, it is assumed that he has lost concentration, for this reason the system sends the first alert (Fig. 5) and changes the display color in yellow. If the learner still does not use the keyboard or mouse, after 10 seconds, the system sends the second alert (Fig. 6) and the display is changed in red color. The present learning situation of the learner is checked by the teacher using his Web site as shown in Fig. 7. In the left frame of the page are shown the students who are using the system, their ID, learning situation, SOS (students that have problems with learning materials) and Alert.

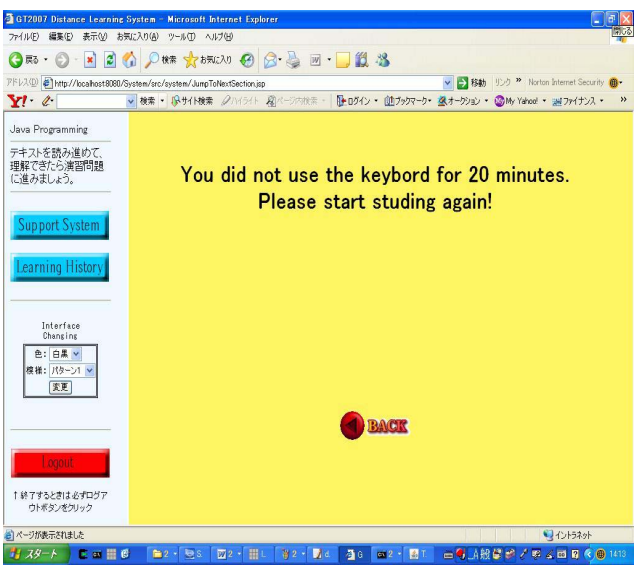

Fig. 5. First alert.

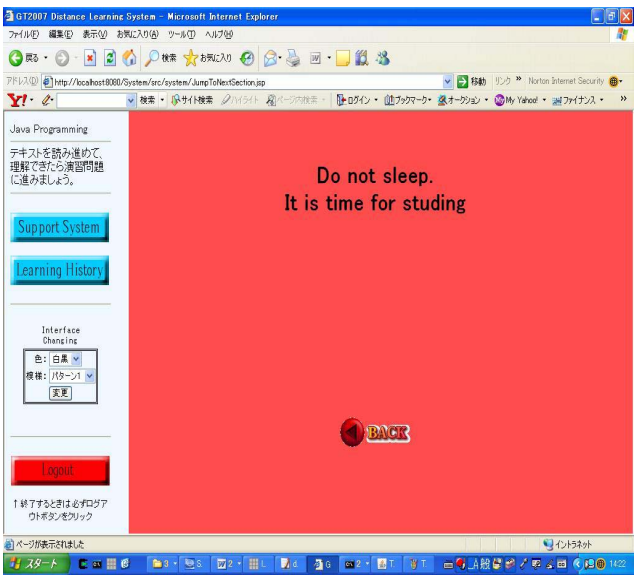

Fig. 6. Second alert.

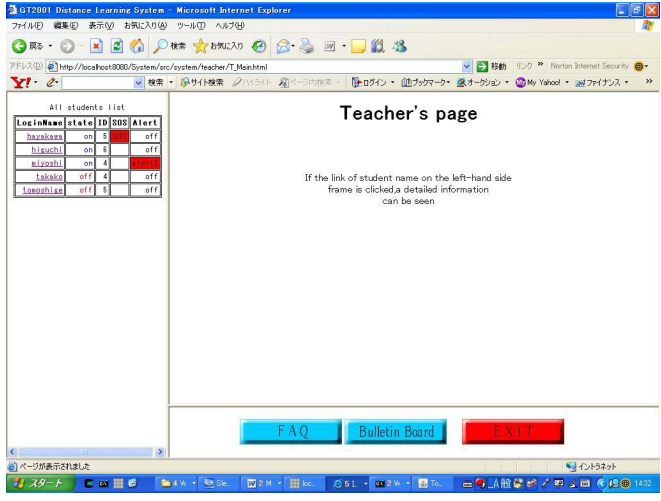

Fig. 7. Teacher page.

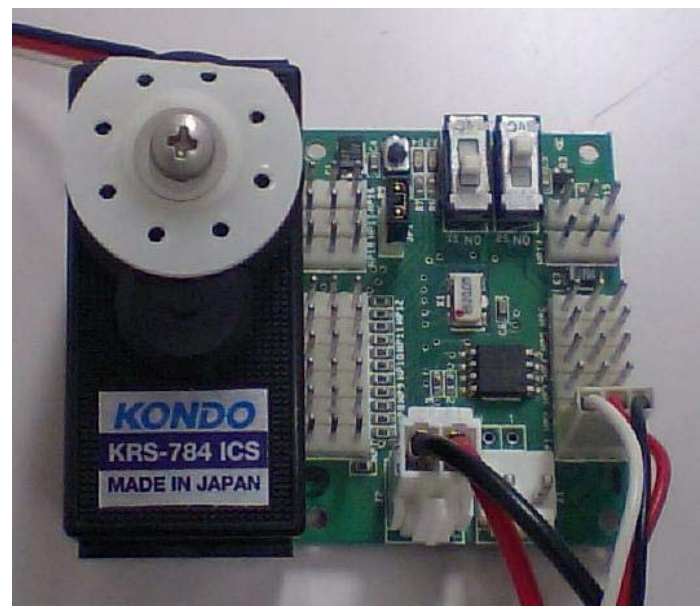

Fig. 8. Chair motor control.

\subsection{Sound emission functions}

In the case when the learner does not change his behavior, the system emits a relaxing sound to change the mood of learner. Another function is implemented using the cellular phone. We used the sound function of cellular phone to send some music to the learner.

\subsection{Vibration functions}

In the case when the learner still does not react we considered the vibration function. We realized this function by using the vibration function of the cellular phone. Another implementation was carried out using a motor in the chair. We can control the motor of the chair by our implemented system as shown in Fig. 8. By changing the angle of the motor, the system can change the learner mood. 


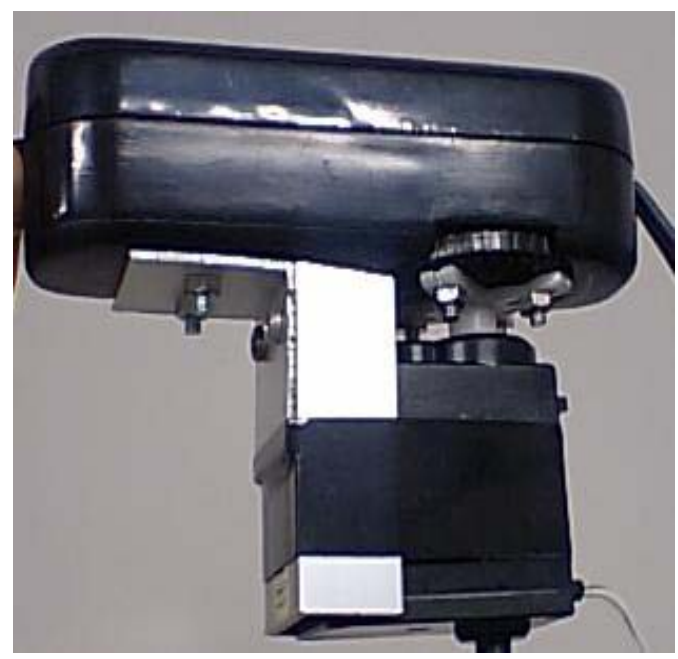

Fig. 9. Room light control.

\subsection{Room light control function}

In our system, we also designed and implemented the room light control function. By this function, we can change the room brightness and stimulate learner's to increase the learning efficiency. The snapshot of implemented system is shown in Fig. 9.

\subsection{Ranking function}

In the previous system, we used a ranking function that displayed the results of the learner that had an average result more than a predefined value. However, this may cause some problems for learners if they results are not good. For this reason in the proposed system, we implemented a new ranking function as shown in Fig. 10. The ranking method is as follows. We divide the learners in different ranks such as A (90 to 100 points), B (80 to 89 points), C (70 to 79 points), D (60 to 69 points) and $\mathrm{E}$ (0 to 59 points). If a learner is ranked in A or B rank, the system shows the other learners that have 10 points more and 5 points less than the present learner. If the learner is ranked in $\mathrm{C}$ or $\mathrm{D}$ rank, the system shows the other learners that have 5 points more and 5 points less than the present learner. Otherwise, if the learner is ranked in E rank, the system does not display the results. Also, if a learner wants to check his studying situation and history, the system can show the ranking level for each item as shown in Fig. 11.

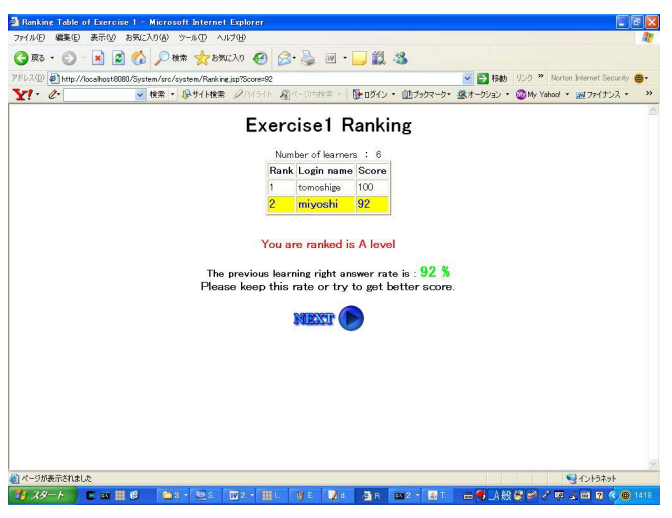

Fig. 10. Ranking function.

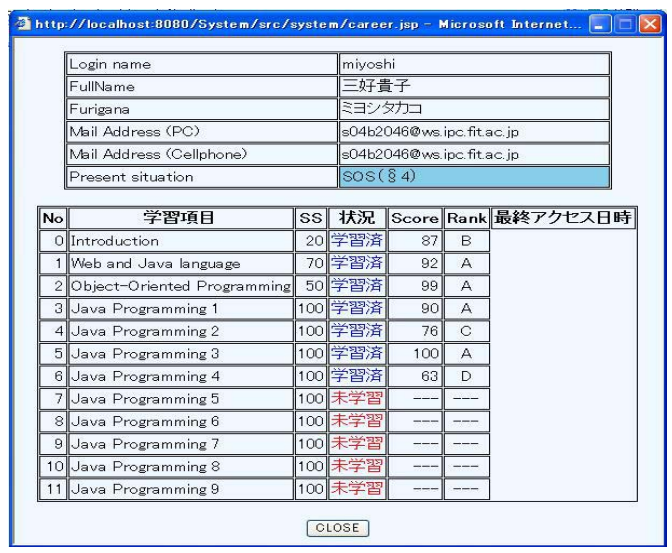

Fig. 11. Learning history.

\section{Comparison of Previous Systems and Proposed System Functions}

In this section, we compare the functions of the proposed system with MESIA system and our previous system as shown in Table 1 . In the proposed system the same with previous system the $\mathrm{BB}$ is used to give the hints by teacher, but in MESIA the hints are used to advice the learners on wrong answers and HELP/MORE for guiding learners to correct answers. As test function, MESIA uses a short test, while in our previous system and the proposed system the learner repeats the exercises until he passes the test. For teacher-student interaction, MESIA uses messages, while in our previous system and the proposed system is used e-mail. In the case when a learner wants to ask the teacher a question, in MESIA is used an online message or video meeting. While, in our previous system and proposed system, the teacher answers the student's question by e-mail or using WM. 
Table 1. Comparison between functions of different systems.

\begin{tabular}{|c|c|c|c|}
\hline Functions & MESIA & $\begin{array}{l}\text { Previous } \\
\text { System }\end{array}$ & $\begin{array}{c}\text { Proposed } \\
\text { System }\end{array}$ \\
\hline Hints & 0 & 0 & 0 \\
\hline Tests & 0 & 0 & 0 \\
\hline $\begin{array}{c}\text { Teacher } \\
\text { Student } \\
\text { Interaction }\end{array}$ & 0 & 0 & 0 \\
\hline $\begin{array}{l}\text { Students } \\
\text { Questions }\end{array}$ & 0 & 0 & 0 \\
\hline $\begin{array}{c}\text { Network } \\
\text { Environment }\end{array}$ & 0 & 0 & 0 \\
\hline $\begin{array}{c}\text { Synchronous } \\
\text { Learning }\end{array}$ & 0 & 0 & 0 \\
\hline $\begin{array}{l}\text { Asynchronous } \\
\text { Learning }\end{array}$ & $x$ & 0 & 0 \\
\hline $\begin{array}{l}\text { Ranking } \\
\text { Function }\end{array}$ & $x$ & $\Delta$ & 0 \\
\hline $\begin{array}{l}\text { Interface } \\
\text { Change } \\
\text { Function }\end{array}$ & $x$ & $\Delta$ & 0 \\
\hline $\begin{array}{l}\text { Vibration } \\
\text { Function }\end{array}$ & $x$ & $x$ & 0 \\
\hline $\begin{array}{l}\text { Sound } \\
\text { Emission } \\
\text { Function }\end{array}$ & $x$ & $x$ & 0 \\
\hline $\begin{array}{c}\text { Room Light } \\
\text { Control } \\
\text { Function }\end{array}$ & $x$ & $x$ & 0 \\
\hline
\end{tabular}

The MESIA is used in the Intranet environment, while the previous system and proposed system are Web-based application and can be used in Internet environment.

In order to have an efficient study, in MESIA the student and the teacher use a synchronous interaction. The previous and proposed system can be used for synchronous and asynchronous learning. MESIA does not have a function to stimulate the learner's motivation, while in our previous system has the display of learner's study history, change of interface color in manual way, encourage function, ranking function, and self-determination of the study materials. Our proposed system has all these functions. We also implemented the following functions: a new ranking function, automatic interface change function, vibration function, room light control function and sound emission function.

\section{Conclusions and Future Work}

In this paper, we improved our previous Web-based e-learning system by implementing new functions such as: a new ranking function, automatic interface change function, vibration function, room light control function and sound emission function. By using these new functions, the proposed e-learning system can increase learner's efficiency by stimulating learner's motivation.

In the future, we want to evaluate the proposed system and its new functions in a real environment. We also want to deal with following problems: learner's privacy, system security, and improving the encouraging function by using not only text but also the animations.

\section{References}

[1] K. Nakabayashi, Y. Koike, M. Maruyama, H. Touhei, Y.Fukuhara, Y. Nakamura, "CALAT: An Intelligent CAI System Using WWW", Trans. of IEICE, D-II, Vol.80, No.4, pp.906-914, 1999.

[2] Blackboard and WebCT, http://www.blac kboard.com/webct.

[3] CALAT Project, "Nippon Telegraph and Telephone Corporation", http://www.calat. $\mathrm{com} /$.

[4] CALsurf, NTT Software Corporation, http:// webbase.ntts.co.jp/.

[5] The University of The Air, http://www. u-air.ac.jp/.

[6] California Virtual University, http://www. california.edu/.

[7] WIDE University, School of Internet. http://www.sfc.wide.ad.jp/soi/ contents.html.

[8] T. Kuwabara, M. Tamaki, K. Yamada, Y. Nakamura, Y. Mistunaga, N. Konishi, K. Amano, "Support Functions for Stalled Students and Their Effect in a Multi-Media Assisted Education System with Individual Advance (MESIA)", Transactions of IEICE, Vol. J83-D-I, No.9, pp.1013-1024, 2000.

[9] L. Barolli, A. Koyama, "A Distance Learning System for Delivering Appropriate Studying Materials and Stimulating Learner Volition", Journal of Distance Education Technologies (JDET), Vol.2, No.1, pp.1-17, 2004.

[10] L. Barolli, A. Koyama, A. Durresi, G. De Marco, "A Web-based E-learning System for Increasing Study Efficiency by Stimulating Learner Motivation", Journal of Information Systems Frontiers, Springer Publishers, Vol. 8, No. 4, pp. 297-306, September 2006. 